\title{
DEMONSTRATION OF MASS TRANSFER USING AERATION OF WATER
}

\author{
Sultana R. Syeda*, B.M. S. Arifin, Md. M. Islam and Anup Kumar \\ Department of Chemical Engineering, Bangladesh University of Engineering and Technology (BUET), \\ Dhaka 1000, Bangladesh
}

\begin{abstract}
An experiment was developed using aeration of water for demonstrating the phenomenon of mass transfer. The demonstration was designed to provide both conceptual and practical insight of the mass transfer process. A bubble column fitted with a sieve tray was used to carry out the experiment. The air flow rate and hole size of the sieve tray were varied. Mass transfer coefficient was obtained from the initial and final oxygen concentrations of the aerated water. A dimensionless correlation for mass transfer coefficient in terms of the experimental variables was developed by dimensional analysis and regression of the experimental data. The demonstration is suitable for chemical and other engineering students and can be fit in one laboratory session of three hours. The experimental setup is simple and inexpensive, and can be developed in-house. In addition to the laboratory demonstration, the experiment can also be used for optimizing design parameters of industrial aeration tanks.
\end{abstract}

Keywords

mass transfer coefficient; aeration; bubble column; dimensional analysis; Stanton number.

\section{Introduction}

Although diffusional mass transfer is of common interest in physics, physical chemistry, biology etc., the concept of mass transfer coefficient is developed explicitly in chemical engineering. A chemical engineering graduate is expected not only to have clear understanding of the concept but also to be comfortable in applying it in diversified fields. Several mass transfer experiments are currently used in the unit operations laboratories of chemical engineering departments in different universities. It is unfortunate that undergraduate laboratories of chemical engineering all over the world is generally lacking in experimental facilities that demonstrates the concept of mass transfer coefficient adequately. A typical chemical engineering laboratory has either a distillation or an absorption column and a diffusion cell with membrane separator. The distillation/absorption column is used to demonstrate tray or packing efficiency and at times to exercise the column control. The diffusion cell, on the other hand, demonstrates diffusion phenomenon and measurement of diffusivity. The notion of mass transfer coefficient is missing from these experimental demonstrations. On the other hand, another similar concept i.e. heat transfer coefficient is dealt in detail in most of the undergraduate laboratories. At least three to five different experimental rigs can be found in a typical chemical engineering undergraduate laboratory for the measurement of heat transfer coefficient, which include study of double pipe heat exchanger, shell and tube heat exchanger, vertical tube and horizontal tube condensation, pool boiling etc. While study of heat transfer comprises an important part

\footnotetext{
*Corresponding Author's Email : syedasrazia@che.buet.ac.bd
}

of chemical engineering, mechanical engineering, industrial production engineering and other related studies, study of mass transfer is unique for chemical engineering and thus, demands special attention from the chemical engineering educators.

Therefore, efforts to build customized experimental set-up are going on to meet the requirement. A number of inexpensive and simple experiments in mass transfer are reported in articles published in Chemical Engineering Education. Nirdosh and Baird (1996-2001) described a series of low cost experiments in mass transfer exploring phenomena of liquid-liquid extraction, gas absorption, vapor diffusion and natural convection. Kwon et al (2002) and Mohammad (2000) have developed experiment to measure binary molecular diffusion and molecular diffusivity. Chawla and Pourhashemi (2004) reported an experimental set-up using both de-oxygenation and aeration to demonstrate the mass transfer phenomenon.

In the present paper our target is to set up a tailored experiment for undergraduate laboratory that can enable students to comprehend both theoretical and applied side of inter-phase mass transfer and mass transfer coefficient. This involves building a simple and easy to maintain experimental rig for demonstrating measurement of mass transfer co-efficient and effect of different parameters on it. A basic mass transfer correlation is also developed using the measured values and a method called dimensional analysis as an essential part of the experiment. The formulation of the experiment is inspired by the aeration set-up suggested by Cussler (1997). Aeration is a frequently used industrial processe, 
particularly as fermentors and in sewage treatment; and is directly relevant to chemical engineering jobs.

This paper describes the experimental set-up, procedure and development of the dimensionless correlation in detail. It also discusses the limitations of the demonstration and scope of further development.

\section{Experimental Set-up and Measurement of Mass Transfer Coefficient}

The aeration process was studied by injecting air into water for a certain period of time and measuring the oxygen concentration of the water before and after the aeration. A glass column of $50.8 \mathrm{~mm}$ diameter and 600 $\mathrm{mm}$ height was built to carry out the aeration experiment. The column was fitted with a sieve tray at the bottom. A manometer was attached to one of the holes of the sieve tray to measure the clear liquid height on the tray. The schematic of the setup is shown in figure 1. At first, the column was filled with $500 \mathrm{ml}$ water. Prior to the experiment, the dissolved oxygen of the feed water, denoted by $c_{10}$, was measured by a DO meter.

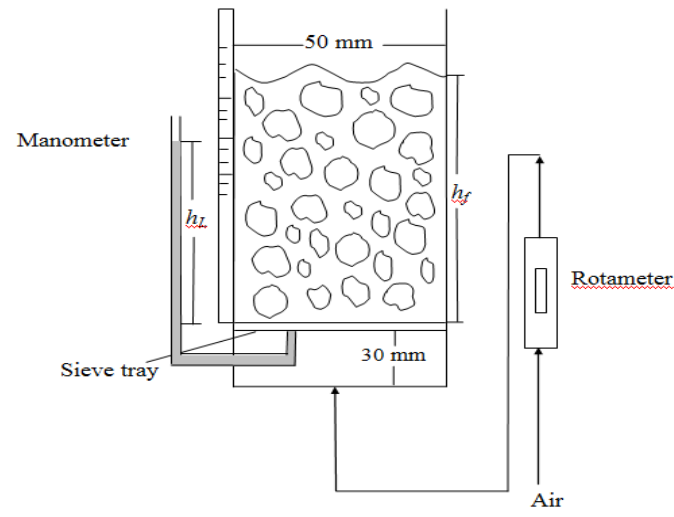

Fig 1. Experimental arrangement for aeration.

Air from a compressor was passed into the water through the sieve tray acting as a sparger. There is a $30 \mathrm{~mm}$ gap between the air inlet and the sieve tray to allow uniform distribution of air over the column cross sectional area. A Rota-meter was used to measure the air flow rate. The flow time was 5 minutes for each experiment. At the end of experiment the aerated water was collected by the drainage valve and concentration of dissolved oxygen of the water, denoted by $c_{1 f}$, was measured. The experiments were carried out at atmospheric condition $\left(\right.$ at $29^{\circ} \mathrm{C}$ and 1 atm). Table 1 summarizes different parameters of the experiment.

A mass balance on the aerated water was done to get the expression for mass transfer coefficient;

$\frac{d V c_{1}}{d t}=A N_{1}=k\left(c_{1, \text { sat }}-c_{1}\right)$ $\frac{d c_{1}}{d t}=k \frac{A}{V}\left(c_{1, s a t}-c_{1}\right)=k a\left(c_{1, s a t}-c_{1}\right)$

Here, $A$ is the interfacial area of mass transfer i.e. total bubble ares, $\mathrm{z}$ is the clear liquid height, $k$ is the mass transfer coefficient, $a$ is the total bubble area per unit volume of liquid, $c_{l}$ is the concentration of the dissolved oxygen in water and $c_{1, s a t}$ is the saturated concentration of the dissolved oxygen in water at atmospheric temperature.

The boundary conditions for equation (1) are

at $\mathrm{t}=0 \quad c_{1}=c_{10}$ and

at $\mathrm{t}=5 \min c_{l}=c_{1 f}$

By integrating equation (1) between the boundaries we get

$$
\begin{aligned}
& \int_{0}^{5} k a d t=\int_{c_{10}}^{c_{1 f}}\left(\frac{d c_{1}}{c_{1, \text { sat }}-c_{1}}\right) \\
& k a=-\frac{1}{5} \ln \left(\frac{c_{1, \text { sat }}-c_{1 f}}{c_{1, \text { sat }}-c_{10}}\right)
\end{aligned}
$$

In present study different air velocities and sieve trays with different hole sizes were used and corresponding $k a$ were calculated from $c_{10}$ and $c_{1 f}$ data using equation (3).

Table 1. Experimental conditions for aeration.

\begin{tabular}{|l|l|}
\hline Diameter of the bubble column & $50.8 \mathrm{~mm}$ \\
\hline Volume of each solution & $500 \mathrm{ml}$ \\
\hline Diameter of single orifice & $3,3.5$ and $4 \mathrm{~mm}$ \\
\hline Number of orifices & 20 \\
\hline Air flow rate & $\begin{array}{l}4,6,8,10 \quad \text { and } 12 \\
\text { it/min }\end{array}$ \\
\hline Aeration time & $5 \mathrm{~min}$ \\
\hline $\begin{array}{l}\text { Initial oxygen content of the } \\
\text { feed water }\end{array}$ & $2.85 \mathrm{mg} /$ lit at $25^{\circ} \mathrm{C}$ \\
\hline $\begin{array}{l}\text { Oxygen content of saturated } \\
\text { water }\end{array}$ & $8.38 \mathrm{mg} /$ lit at $25^{\circ} \mathrm{C}$ \\
\hline
\end{tabular}

For better result, $k$ and $a$ should be measured independently. The product of $k a$ is measured to avoid the uncertainty and difficulties arise in individual measurement of $k$ and $a$.

\section{Development of Dimensionless Correlation}

The method dimensional analysis is frequently used in describing transport phenomena, i.e. mass transfer, momentum transfer, heat transfer etc and a useful tool for 
engineers in general. Mass transfer modeling is traditionally done by dimensional analysis. The accuracy of a dimensional analysis is dependent on proper identification of the factors affecting the phenomenon. In this demonstration the main experimental variables are bubble velocity, $v$, bubble diameter, $d$, liquid density, $\rho$, liquid height, $\mathrm{z}$ and viscosity, $\mu$. Thus, $k a$ can be expressed as a function of five factors

$$
k a=k a(v, \rho, \mu, d, z)
$$

The function is assumed to have the following form

$$
k a=C v^{\alpha} \rho^{\beta} \mu^{\gamma} d^{\delta} z^{\kappa}
$$

Here, the constant $C$ and the exponents $\alpha, \beta, \gamma, \delta$ and $\kappa$ are dimensionless.

From dimensionless analysis the following equation is obtained

$$
\frac{k a d}{v}=C\left(\frac{d v \rho}{\mu}\right)^{-\gamma}\left(\frac{z}{d}\right)^{\kappa}
$$

The left hand side of equation (6) is a type of Stanton number whereas the first term in parentheses on the right hand side is Reynolds number and the second term is a measure of column's depth. The next step of the correlation development is to determine the constant $C$ and the exponents $\gamma$ and $\kappa$. By taking $\ln$ on both sides of equation (6) we get

$\ln \left(\frac{k a d}{v}\right)=\ln C-\gamma \ln \left(\frac{d v \rho}{\mu}\right)+\kappa \ln \left(\frac{z}{d}\right)$

In this demonstration the bubble diameter is considered to be independent of velocity. Therefore, if the sieve tray is kept fixed and air flow rates were varied, the plot of $\ln \left(\frac{k a d}{v}\right) \operatorname{vs} \ln \left(\frac{d v \rho}{\mu}\right)$ will produce a straight line with slope $-\gamma$ and intercept $\left(\ln C+\kappa \ln \left(\frac{z}{d}\right)\right)$.

Furthermore, equation (7) can be rearranged to get the value of $\kappa$ as follows

$\ln \left[\left(\frac{k a d}{v}\right) \times\left(\frac{d v \rho}{\mu}\right)^{\gamma}\right]=\ln C+\kappa \ln \left(\frac{z}{d}\right)$

According to equation (8), a plot of $\ln \left[\left(\frac{k a d}{v}\right) \times\left(\frac{d v \rho}{\mu}\right)^{\gamma}\right]$ against $\ln \left(\frac{z}{d}\right)$ will form a straight line with slope $\kappa$ and intercept $\ln C$.

\section{Determination of the Exponents and the Constant}

In order to determine the exponents and constant $\mathrm{C}$, aeration was done with sieve trays of three hole sizes and five air flow rates. The ka values were estimated with the initial and final concentrations of oxygen of the aerated water using equation (1). Table 2 presents the calculated values of ka for

\begin{tabular}{|c|c|c|}
\hline $\begin{array}{c}\text { Hole } \\
\text { diameter } \\
(\mathrm{mm})\end{array}$ & $\begin{array}{l}\text { Air flow rate } \\
\text { (lit/min) }\end{array}$ & $k a\left(\mathrm{~s}^{-1}\right)$ \\
\hline \multirow{5}{*}{3} & 4 & $2.0833 \times 10^{-3}$ \\
\hline & 6 & $2.1631 \times 10^{-3}$ \\
\hline & 8 & $2.3045 \times 10^{-3}$ \\
\hline & 10 & $2.5028 \times 10^{-3}$ \\
\hline & 12 & $2.0721 \times 10^{-3}$ \\
\hline \multirow{5}{*}{3.3} & 4 & $1.1812 \times 10^{-3}$ \\
\hline & 6 & $1.5439 \times 10^{-3}$ \\
\hline & 8 & $1.5824 \times 10^{-3}$ \\
\hline & 10 & $1.8866 \times 10^{-3}$ \\
\hline & 12 & $1.6509 \times 10^{-3}$ \\
\hline \multirow{5}{*}{4} & 4 & $1.1385 \times 10^{-3}$ \\
\hline & 6 & $1.2506 \times 10^{-3}$ \\
\hline & 8 & $1.3215 \times 10^{-3}$ \\
\hline & 10 & $1.3667 \times 10^{-3}$ \\
\hline & 12 & $1.2859 \times 10^{-3}$ \\
\hline
\end{tabular}
different runs.

Table 2. $k a$ values for different operating conditions

The bubble diameter, $d$ and bubble velocity, $v$ were estimated by the following equations;

$$
\begin{aligned}
& d=1.27\left(\frac{D_{H} \sigma}{g\left(\rho_{l}-\rho_{g}\right)}\right)^{1 / 3} \\
& v=25 V^{1 / 6}+U_{s}
\end{aligned}
$$

Here, $U_{s}$ is the superficial velocity of air, $D_{H}$ is the hole diameter of the sieve tray, $V$ is the bubble volume and $\sigma$ is the surface tension of water. The parameters $\left(\frac{k a d}{v}\right),\left(\frac{d v \rho}{\mu}\right)$ were calculated using the $k a$, $d$ and $v$ values. Figure 2 and 3 present the plot 
$\ln \left(\frac{k a d}{v}\right)$ vs $\ln \left(\frac{d v \rho}{\mu}\right)$ and $\ln \left[\left(\frac{k a d}{v}\right) \times\left(\frac{d v \rho}{\mu}\right)^{\gamma}\right]$ vs

$\ln \left(\frac{z}{d}\right)$, respectively.

The linear regression lines are also shown in the figures. The constant and exponents of equation (6) obtained from the slope and intercepts of the regression lines are shown in Table 3.
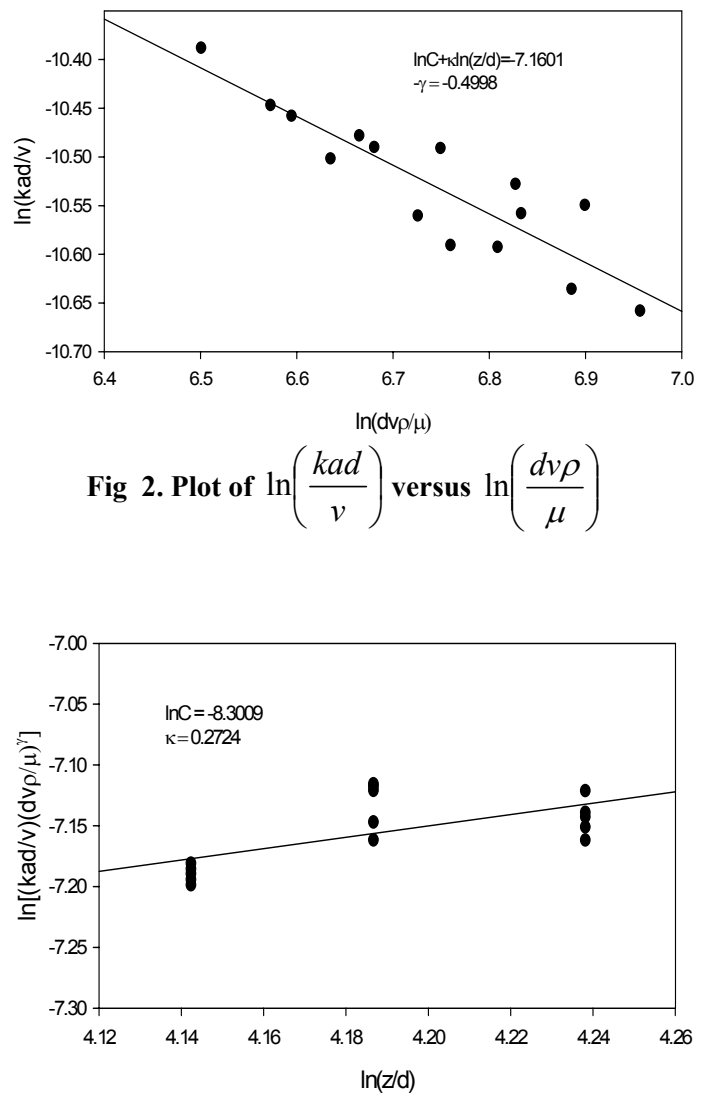

Fig 3. Plot of $\ln \left[\left(\frac{k a d}{v}\right) \times\left(\frac{d v \rho}{\mu}\right)^{\gamma}\right]$ versus $\ln \left(\frac{z}{d}\right)$

Table 3. Exponents and constant obtained from regression analysis

\begin{tabular}{|c|c|c|}
\hline$\gamma$ & $\kappa$ & $\mathrm{C}$ \\
\hline 0.4998 & 0.2724 & $2.5 \times 10^{-4}$ \\
\hline
\end{tabular}

\section{Results and Discussions}

The experimental values of ka varied from $1.1385 \times 10-3$ to $2.5 \times 10-3$ per sec, which are within the typical range of mass transfer coefficient in liquids. The correlation gives $\mathrm{ka}$ as a function $\mathrm{v} 0.5$, which is also within the acceptable range as the exponent to $\mathrm{v}$ in the existing correlations of ka varies from 0.2 to 0.6 for liquid system (Cussler, 1997).

In this demonstration it is also important to appreciate the sources of error in the measurement as well as the shortcomings of dimensional analysis. For example, low airflow rate leads to weeping through the sieve tray. This affects the measurement of liquid height, $\mathrm{z}$ and dissolved oxygen of the aerated liquid, c1f. Furthermore, fluctuation in air flow introduces error in measurement by affecting the bubble diameter and bubble velocity. These can be minimized by keeping the flow rate high enough to avoid weeping and by introducing an intermediate storage tank between the compressor and the air inlet to the column to stabilize the fluctuation of air flow.

Furthermore, the variables considered in the dimensional analysis are not exhaustive. $k a$ may vary with tank diameter, sparger shape or surface tension of the liquid. This will change the form of the correlation developed as equation (6). In this demonstration, the clear liquid height, $z$ was kept fixed and $z / d$ were varied by varying the hole diameter of the sieve tray. A better estimation may be obtained by varying the liquid height, $z$. Besides, equation (9) does not include effects of hole velocity on bubble diameter, which is not always the fact. Bubble diameter may be directly obtained by image processing instead of calculating from other parameters.

\section{Conclusions}

In this work, aeration of water was studied to demonstrate mass transfer coefficient measurement in the undergraduate laboratory of chemical engineering. The product of mass transfer coefficient and total bubble area per column volume, $k a$ were measured experimentally. A correlation was developed by dimensional analysis to express $k a$ in terms of the experimental variables. This demonstration is unique as it offers a simple and easy to maintain experimental procedure and provides useful training in the area of mass transfer operations to undergraduate students in the Chemical, Environmental Engineering and other relevant disciplines.

Finally, due to growing environmental concern and demand of biochemical processes a considerable amount of expense is being involved in providing oxygen in aeration of water and wastewater. Efficient distribution of oxygen in the bioreactors or treatment tanks is a major design criterion and requires a good understanding of the mass transfer mechanism. The developed correlation i.e. equation (6a) may be used to optimize design and operating parameters of industrial aeration tanks.

\section{Nomenclature}

a total bubble area per liquid volume, $\mathrm{cm}^{2} / \mathrm{cm}^{3}$

A cross sectional area of the column, $\mathrm{cm}^{2}$

$c_{1} \quad$ oxygen concentration of the aerated water $\mathrm{mg} / \mathrm{cc}$ 


$\begin{array}{ll}c_{1(\text { sat })} & \begin{array}{l}\text { saturation oxygen concentration of the water, } \\ \mathrm{mg} / \mathrm{cc}\end{array} \\ C & \text { Constant in equation (6) } \\ d & \text { bubble diameter, } \mathrm{cm} \\ D_{H} & \text { sieve diameter, } \mathrm{m} \\ k & \text { mass transfer coefficient, } \mathrm{cm} / \mathrm{s} \\ U_{s} & \text { superficial velocity, } \mathrm{cm} / \mathrm{s} \\ v & \text { superficial velocity of air, } \mathrm{cm} / \mathrm{s} \\ V & \text { volume of bubbles, } \mathrm{cm}\end{array}$

\section{Symbols}

$\gamma, \kappa \quad$ exponents in equation (6)

$\mu \quad$ viscosity, $\mathrm{g} / \mathrm{cm}-\mathrm{s}$

$\rho_{g} \quad$ density of air, $\mathrm{g} / \mathrm{cc}$

$\rho_{l} \quad$ density of water, $\mathrm{g} / \mathrm{cc}$

$\sigma \quad$ surface tension of water, $\mathrm{g} / \mathrm{m}-\mathrm{s}$

\section{References}

1. Chawla, R. C. and Pourhashemi, A., (2004), Mass Transfer Experiment Using Deoxygenation and Aeration of Water, Proceedings of the 2004 American Society for Engineering Education Annual Conference \& Exposition.

2. Cussler, E. L., Diffusion Mass Transfer in Fluid Systems(1997), $2^{\text {nd }}$ edition, Cambridge University Press, 248-249.

3. Kwon, K.C., Ibrahim, T.H., Park, Y. K. and Simmons, C. M. (2002), Inexpensive and Simple Binary Molecular Diffusion Experiments, Chemical Engineering Education, Vol. 36, No.1.

4. Mohammad, A. W.(2000), Simple Mass Transfer Experiment Using Nanofiltration Membranes, Chemical Engineering Education, Vol. 34, No.3.

5. Nirdosh, I. and Baird, M. (1996 - 2001), Low-Cost Experiments in Mass Transfer, Parts 1-8, Chemical Engineering Education, Vol. 30, No.1 to Vol. 35, No.3. 